\title{
Research Experiences For Teachers: Linking Research to Teacher Practice and Student Achievement
}

\section{Dr. Gisele Ragusa, University of Southern California}

Dr. Gisele Ragusa is an associate professor at the University of Southern California (USC) in the Viterbi School of Engineering in the Division of Engineering Education. She co-directs USC's STEM Education Consortium. Her research interests and areas of expertise include: engineering education, engineering innovation and global preparedness, college access, STEM K-12 education and teacher education, STEM literacy education, as well as assessment and measurement in STEM education. She teaches courses in research design, measurement theory, critical pedagogy in STEM and courses in learning and instructional theory. She extensive expertise in assessment, psychometrics, advanced quantitative analyses, and multimodal research design. She is active in many professional associations in the engineering and science education, teacher education, distance learning, program evaluation and special education fields. She has been the principal investigator on several federal grants through the US Department of Education, the National Institute of Health, and the National Science Foundation.

\section{Dr. Maja J. Mataric, University of Southern California}

Maja Mataric is professor and Chan Soon-Shiong chair in Computer Science, Neuroscience, and Pediatrics at the University of Southern California, founding director of the USC Center for Robotics and Embedded Systems (cres.usc.edu), co-director of the USC Robotics Research Lab (robotics.usc.edu) and Vice Dean for Research in the USC Viterbi School of Engineering. She received her PhD in Computer Science and Artificial Intelligence from MIT in 1994, MS in Computer Science from MIT in 1990, and BS in Computer Science from the University of Kansas in 1987. She is a Fellow of the American Association for the Advancement of Science (AAAS), Fellow of the IEEE, and recipient of the Presidential Awards for Excellence in Science, Mathematics \& Engineering Mentoring (PAESMEM), the Anita Borg Institute Women of Vision Award for Innovation, Okawa Foundation Award, NSF Career Award, the MIT TR100 Innovation Award, and the IEEE Robotics and Automation Society Early Career Award. She served as the elected president of the USC faculty and the Academic Senate. At USC she has been awarded the Viterbi School of Engineering Service Award and Junior Research Award, the Provost's Center for Interdisciplinary Research Fellowship, the Mellon Mentoring Award, the Academic Senate Distinguished Faculty Service Award, and a Remarkable Woman Award. She is featured in the science documentary movie "Me \& Isaac Newton", in The New Yorker ("Robots that Care" by Jerome Groopman, 2009), Popular Science ("The New Face of Autism Therapy", 2010), the IEEE Spectrum ("Caregiver Robots", 2010), and is one of the LA Times Magazine 2010 Visionaries. Prof. Mataric is an associate editor of three major journals and has published extensively. She serves or has recently servied on a number of advisory boards, including the National Science Foundation Computing and Information Sciences and Engineering (CISE) Division Advisory Committee, and the Willow Garage and Evolution Robotics Scientific Advisory Boards. Prof. Mataric is actively involved in K-12 educational outreach, having obtained federal and corporate grants to develop free open-source curricular materials for elementary and middle-school robotics courses in order to engage student interest in science, technology, engineering, and math (STEM) topics. Her Interaction Lab's research into socially assistive robotics is aimed at endowing robots with the ability to help people through individual non-contact assistance in convalescence, rehabilitation, training, and education. Her research is currently developing robot-assisted therapies for children with autism spectrum disorders, stroke and traumatic brain injury survivors, and individuals with Alzheimer's Disease and other forms of dementia. Details about her research are found at http://robotics.usc.edu/interaction/.

\section{Dr. Shaobo Huang, University of Southern California}

Shaobo Huang is a Post-Doctoral Research Associate in STEM Education in the School of Engineering at the University of Southern California (USC). With BS and MS degrees in electrical engineering, she received her Ph.D. in Engineering Education at Utah State University (USU). Her areas of interest include 


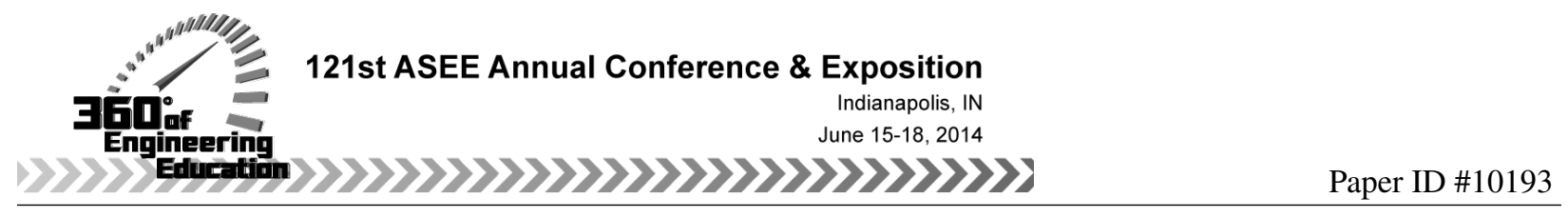

increasing retention rates in engineering, and improving academic performance of minority students in STEM disciplines.

\section{Dr. Svetlana Levonisova, University of Southern California}




\title{
Research Experiences For Teachers: Linking Research to Teacher Practice and Student Achievement
}

\begin{abstract}
Research identifies a national urgency to improve teacher performance and student achievement in science and engineering. This paper responds to this need and presents the results of a four year Research Experience for Teachers (RET) program funded by the National Science Foundation in which engineering faculty collaborate with middle and high school teachers and their students. The Societally Relevant Engineering Technologies (SRET) RET program is a comprehensive teacher professional development program in which middle and high school teachers participate in an intensive summer research experience in engineering labs, build curriculum based on the laboratory research content that they learn, participate in lesson study, and implement new curriculum in their middle or high school classrooms. The program has the combined intent of bringing innovative engineering research to middle and high school students and improving student achievement through scientific inquiry. The program's design includes a summer intensive experience in which teachers fully participate in engineering laboratory research and engage in an inquiry focused content-to-pedagogy teacher professional development workshop, building curriculum from their lab research experience with foci on scientific experimentation and improving students' science achievement and literacy. The program is aligned with Common Core Math Standards and Next Generation Science Standards and addresses the research question:
\end{abstract}

- What is the impact of an intensive research-based teacher professional development program on teacher and student performance?

Thirty-one middle and high school teachers and their 3,923 students have participated in the SRET RET program. Assessment metrics used to measure the impact of the program are: a teacher instructional performance metric, the Science Teaching Efficacy Beliefs Instrumentrevised, a science qualitative reading inventory, grade and content specific concept inventories, and a motivation for science questionnaire. Program results are: the teachers had a mean science teaching efficacy higher than the national average. The mean score on teacher performance rating was higher than the state's average rating. The SRET RET teachers had a significant performance gain pre to post program. Results also indicate that students made significant gains during their curricular intervention resulting from their teachers' participation in the RET program. Students gained science and engineering knowledge, increased their science interest and motivation, and demonstrated gains in science literacy as well.

Introduction and program need

There is a growing national concern over decreases in science achievement in middle school. Paired with it are challenges associated with workforce declines in STEM-related careers. In response, in a recent PCAST report ${ }^{1}$ recommendations for recruitment of science and engineering students and corresponding recommendations for increased attention to strategic STEM-related instruction and teacher professional development have emerged. A significant 
challenge facing urban science teachers is a low sense of self-efficacy in teaching STEM content. ${ }^{2}$ Additionally, a recent large-scale study of teachers revealed that secondary teachers indicated a strong need for help in the areas of English Language Development (ELD) and content teaching in science, and that a weakness of existing professional development was in the lack of attention to English learners (EL) and the lack of long-term follow up. ${ }^{3}$ This suggests a significant need for professional development of the type offered in this RET program so that all students can benefit, particularly ELs. Intervening with teachers via lesson study and using high quality research in developing middle and high school curricula is an important way of positively impacting student outcomes. These points are essential for strategic intervention connected to professional development for teachers and are precisely the focus of the SRET RET program.

A major reason posited for poor student achievement in science relates to teachers' preparedness. Stigler and colleagues ${ }^{4}$ found that US teachers were quite ill prepared to teach science compared to other nations. In particular, middle school teachers have been found to be unprepared due to their limited science content knowledge and their inability to apply math to science content. ${ }^{5}$ Researchers hypothesize that this is because the majority of middle school teachers are "generalists" in that they often hold elementary multiple subject credentials and achieve their secondary credentials by exam rather than by studying scientific subject matter. With the implementation of the Next Generation Science Standards, which have both contemporary engineering and science at their core, increasing both middle and high school teachers' content knowledge is critical.

While there are many skills needed to teach science effectively, deep interconnected subject matter knowledge is crucial in secondary schools. ${ }^{6}$ Scholars argue that in-service science teachers, particularly in middle and high schools, fall short in their understanding the depth of contemporary science content they are required to teach. ${ }^{7,8}$ For example, Parker et al. ${ }^{9}$ found that, while high school teachers were most likely to have deep science content knowledge, middle school teachers' science knowledge was limited. Only $13 \%$ of studied high school teachers had low levels of science knowledge as opposed to $63 \%$ of middle school teachers. In contrast, $56 \%$ of high school teachers showed high levels of science content knowledge in comparison to $23 \%$ of middle school teachers. The SRET RET program focuses on addressing the content area needs of both middle and high school teachers by immersing them in sciencemath pairs in cutting-edge computer science and engineering labs and guiding them in curricular development using their research experiences as content using a lesson study approach.

\section{Program scope}

The SRET RET program is a program in which engineering faculty collaborate with middle and high school teachers and their students. The program is a comprehensive teacher professional development program in which middle and high school teachers participate in an intensive summer research experience in university engineering labs, build grades 6-12 curriculum based on the laboratory research content that they learn in the labs, and implement the new curriculum in their classrooms. The program has the combined intent of bringing contemporary, innovative engineering research to middle and high school students (in other words bring labs to class) and 
improving student achievement and interest in science and engineering through scientific inquiry.

Key activities

The SRET RET program design and associated activities included a five-week summer intensive experience in which four days per week (9am-4pm) middle and high school teachers fully participated in engineering laboratory research and then one day per week teachers engage in an inquiry focused content-to-pedagogy teacher professional development workshop, building curriculum from their lab research experience with foci on scientific experimentation and improving students' science achievement and literacy. Following the summer intensive research and curriculum building experience, the teachers used the curriculum that they built in their classrooms and engaged in fall and spring semester follow-up. Through this, they engaged in lesson study, studying videotapes of their lessons with one another and engineering faculty with the goal of improving their instructional practices. This follow-up combined lesson study, a proven form of teacher self-study guided by experts, and science literacy professional development. The program is aligned with Common Core Math and English Language Arts content standards and the new national Next Generation Science Standards, which focus on bringing engineering problem solving to America's K-12 classrooms.

The SRET RET program's outcome goals are:

- To increase teachers' content knowledge in science, technology, engineering and mathematics (STEM) through exposure and real life experience conducting innovative research in engineering laboratories.

- To increase teachers' instructional practice focused on STEM student achievement and science literacy through collaborative lesson study and targeted professional development.

- To increase middle and high school students' science achievement and science literacy.

- To increase middle and high school students' motivation, engagement and interest in STEM college majors and eventual careers through exposure to innovative, societally relevant engineering experimentation in their classrooms.

This program has served middle and high school teachers and their students in urban settings. To date, we have served 31 middle and high school teachers and their 3,923 students (combined in four years; 2010-2013). Accordingly, the program had both broad-based and deep impact on teachers and students.

Impact-focused assessment and results

The SRET RET program employs a carefully crafted, outcomes-focused approach that is aligned with a teacher performance to student outcomes assessment logic model. Figure 1 (below) illustrates the links between teacher performance and student outcomes in the model. 
Figure 1: Assessment Logic Model

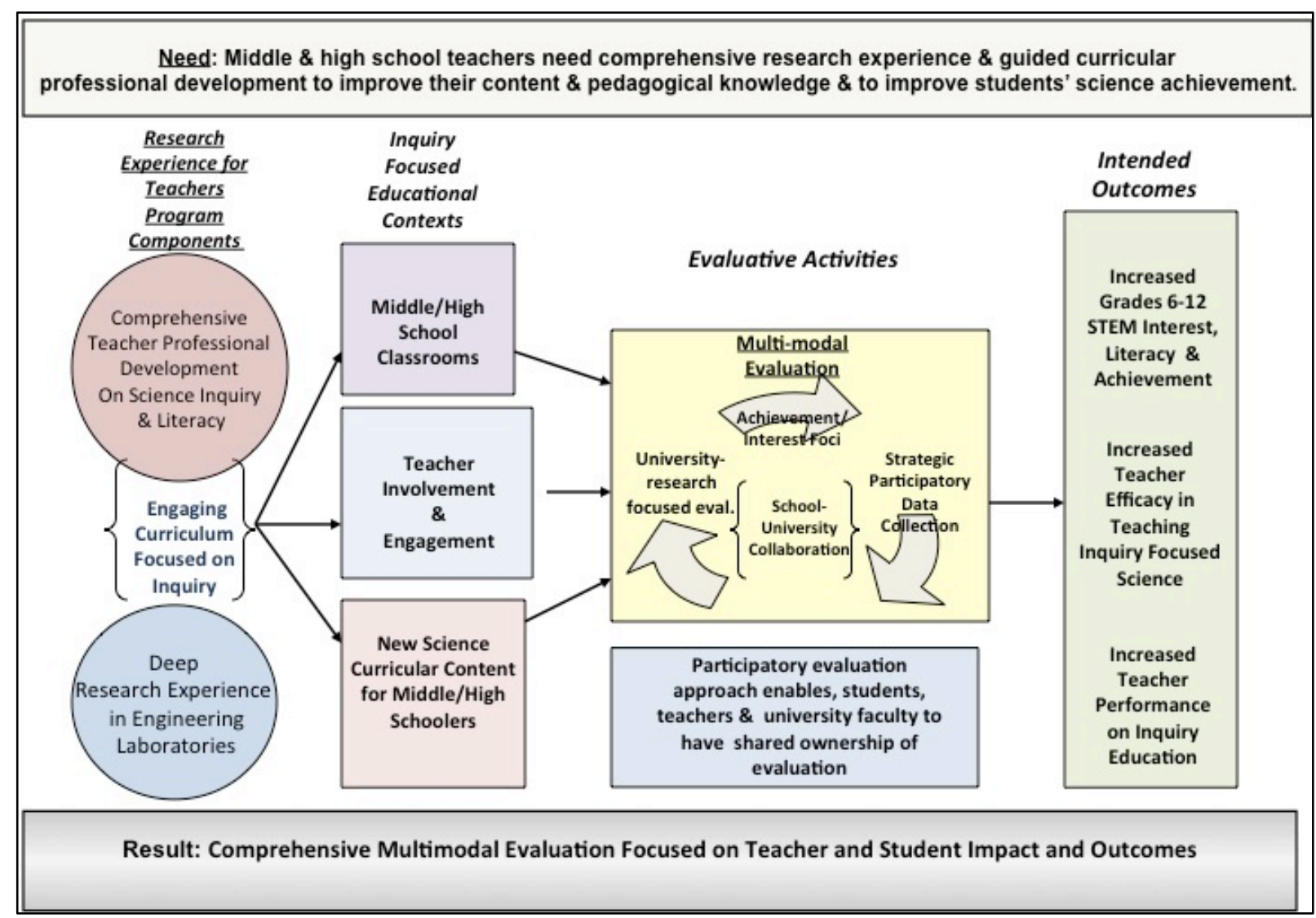

This logic model indicates how each of the program components relates to the intended outcome goals of the SRET RET program.

Aligned with this logic model, five assessment metrics were used to measure the impact of the SRET RET program. Two impact measures were used for teachers and three impact measures were used for students. A description of each measure and associated results follow.

Teacher assessments

- Teacher Instructional Performance Metric: This assessment is a rubric scored observational measure of science teacher instructional performance aligned to the state's teacher performance assessment entitled the Teacher Performance Observational Rubric (TPOR). ${ }^{10}$ Reliability of this instrument is .79 (Cohen's coefficient alpha, NOTE: a score above .70 is considered a statistically reliable instrument). SRET RET participating teachers were observed and their teaching performance was scored based on their instructional performance and practice and compared to a statewide sample of the state's science teachers. 
- $\quad$ Science Teaching Efficacy Beliefs Instrument-Revised (STEBI-R secondary) ${ }^{11}$ : This assessment is a teacher metric and is a measure that assesses teachers' efficacy in teaching science to middle school and high schoolers (in other words their belief that they are a science teacher that can improve students' achievement. The instrument includes personal science teaching efficacy (PSTE) and science teaching outcome expectation (the outcomes that they expect from their students, STOE). The measure was administered with the teachers before they were in the program and after they completed the program to and compared to non-participant science teachers that match the participant teachers socio-demographically (using state and national data) to measure impacts of the program on participating teachers. Reliability of this instrument is .89 (Cohen's coefficient alpha). ${ }^{12}$

Student assessments

- Science Qualitative Reading Inventory: This assessment is an inventory of science vocabulary, reading comprehension, and science writing achievement and is matched to grade level science content and vocabulary in grades 6-12 science content. Range of reliability of this instrument is .79-.83 (Cohen's coefficient alpha). Students whose teachers participated in the SRET RET program were compared to those whose teachers did not participate in the program. Science literacy is an achievement measure and is directly correlated to other science achievement metrics (including standardized statewide achievement tests, $\mathrm{r}=.397, \mathrm{p}<.01$ ) because ability to read and understand science textbooks is critical to understanding science concepts and procedures (including experimentation.) The science reading inventory was administered at the start of the year after the teachers completed the SRET RET experience and then at the end of the year to measure the gains in students' science literacy as a function of the teachers' improved teaching from participating in the SRET RET experience. During the SRET RET experience, the teachers received deliberate professional development on how to effectively use science texts with students to improve their science literacy. As such, we measured the impact of this teacher professional development component.

- Grade and Content Specific Concept Inventories: These inventories measure grade leveled concepts critical to scientific understanding in middle and high school that are aligned with the grades 6-12 science content standards (and in some cases, the math standards as well). These measures have been designed with the teachers and are reflective of SRET RET created unit content. They also are aligned with best practices in item response theory (IRT). ${ }^{13}$ These inventories are achievement measures of concepts directly aligned with the curriculum (lessons) that the teachers created and implemented resulting from the SRET RET experience. These inventories were administered with students before and after the SRET RET lessons to measure achievement gains in science.

- Motivation for Science Questionnaire: This questionnaire measures students' interest, motivation, and engagement in science. Reliability of this instrument is .79 (Cohen's coefficient alpha). Motivation and achievement are directly correlated. Additional motivation and interest in science correlate with students' effort in science coursework and eventual career interest in science fields. 
results $(2010-13)$

The STEBI-R measures teachers' science teaching efficacy. Using three years of teaching efficacy data (a composite) and comparing to a national and state data set as comparative data, we have compared the science teaching efficacy of the SRET RET participants to other national studies using $z$ score adjusted data for multi-construct comparative accuracy. Mean scores for RET participants have been compared to non-RET groups. Table 1 illustrates the comparison of the SRET RET teacher participants on the STEBI-R teacher measure compared to national measures on science teaching efficacy using the same instrument. The RET teachers had a mean science teaching efficacy of 3.29 and the national average (per other published studies) is 2.47. Table 1 also includes SRET RET teacher participants' percentage gains from start to finish of their RET experience in science teaching efficacy (\% gains are computed by denoting the sum score differences pre and post rather than 4-point mean gain).

For a second teacher assessment, we have compared teacher instructional performance using a standardized teacher observational metric, the TPOR (for inservice teachers), to the state's statewide averages. The TPOR is a measure aligned with that which is used to measure instructional performance in preservice and inservice teachers across the state. The mean score on our teacher performance rating (TPOR) for SRET RET participants was 3.24 (partial comparison). The statewide average in single subject science PACT-R rating is 2.89. Our teachers had a 27.7 percent gain pre to post RET program (sum scores were used for this percentage gain statistic). Importantly, we recognize that many factors go into improving teacher performance, and that without controlled comparison, predictions of performance indicators are difficult, however our intention is that statistical comparisons to state and national averages reveals promising SRET RET teacher results from the program.

Full comparative results of the teacher impact metrics thus far are indicated in the table that follows (Tables 1). Results are presented as both means (or averages) and percentage gains during start to finish of the RET teacher "intervention" time period. These results are based on two years of combined teacher research and professional development.

Table 1: Teacher Results 2010-2013

\begin{tabular}{|l|c|c|c|}
\hline Metric & \multicolumn{1}{|c|}{$\begin{array}{c}\text { Post }- \\
\text { Program } \\
\text { Subscale } \\
\text { Ave. }\end{array}$} & $\begin{array}{c}\text { Nat'l } \\
\text { Subscale } \\
\text { Ave. }\end{array}$ & $\begin{array}{c}\text { RET \% } \\
\text { Total } \\
\text { Gains }\end{array}$ \\
\hline $\begin{array}{l}\text { Teacher } \\
\text { Performance } \\
\text { (TPOR/ } \\
\text { PACT) }\end{array}$ & 3.24 & 2.89 & $\mathbf{2 7 . 7}$ \\
\hline $\begin{array}{l}\text { Science } \\
\text { Teaching } \\
\text { Efficacy }\end{array}$ & 3.29 & 2.47 & $\mathbf{2 2 . 3}$ \\
\hline
\end{tabular}


These results indicate that the teachers made gains in performance and efficacy during the SRET RET program and that the SRET RET teacher participants out performed state and national averages on these two metrics.

In addition to conducting teacher performance and efficacy measures, we measured changes in student performance of the teachers who participated in the SRET RET. Specifically, since one of the SRET RET program's intentions is to increase science, technology, engineering and math (STEM) literacy, our curriculum interventions were designed to target science literacy, and we used this metric as a student comparison measure. As such, we designed, administered, and validated a qualitative reading measure for science literacy at both the high school and middle school levels that includes reading comprehension, reading vocabulary in science and writing in science. These data are subject specific and aligned with the newly developed national Common Core standards in English Language Arts by grade level, and the new Next Generation Science Standards, and represent subject specific literacy (e.g. physics literacy, biology literacy, life science literacy, or chemistry literacy.) Results are presented in Table 2 (2010-2013).

We also measured students' motivation, interest and engagement in science. This was done via a motivation for science questionnaire, which is a four-point Likert-type instrument with 11 subscales adapted from Baker and Wigfield's Motivation for Reading Questionnaire. ${ }^{14}$

Finally, with regard to testing the conceptual knowledge gained from our curricular design that the teachers did during the summer SRET RET, we designed and implemented a concept inventory as an achievement test for each teacher-created "unit of study." We have the following results for the student metrics in Table 2 (combined 2010-2013).

Table 2: Student Results (2010-2013)

\begin{tabular}{|l|c|c|c|}
\hline Metric & $\begin{array}{c}\text { Pre- } \\
\text { pgm. \% } \\
\text { Score }\end{array}$ & $\begin{array}{c}\text { Post-pgm. } \\
\text { \% Score }\end{array}$ & $\begin{array}{c}\text { \% } \\
\text { Gains }\end{array}$ \\
\hline $\begin{array}{l}\text { Science Knowledge } \\
\text { (conceptual } \\
\text { understanding) }\end{array}$ & 68.7 & 89.2 & $\mathbf{2 0 . 5}$ \\
\hline Science Literacy & 51.2 & 84.3 & $\mathbf{3 3 . 1}$ \\
\hline $\begin{array}{l}\text { Science Interest \& } \\
\text { Motivation (sum) }\end{array}$ & 57.6 & 81.9 & $\mathbf{2 4 . 3}$ \\
\hline
\end{tabular}

These results indicate that the students (on average) made statistically significant $(\mathrm{P}<.05$ across measures) gains during their curricular intervention resulting from their teachers' participation in the SRET RET program. They gained knowledge, increased their science interest and motivation, and demonstrated gains in science literacy as well. 
The student and teacher focused SRET RET program data have demonstrated that a teacher intervention results in student outcome gains. These gains are statistically significant, indicating success of the SRET RET program.

This research was funded by the National Science Foundation: Societally Relevant Engineering Technologies Research Experience for Teachers SRET RET, DUE-RET 0909243

\section{Bibliographical information}

1. President's Council on Advancement of Science and Technology (PCAST, 2011), Report to Congress on the State of STEM Education. DC. 25-37.

2. National Center for Educational Statistics. (1999). Teacher quality: A report on the preparation and qualifications of public school teachers. Washington, DC: National Center for Educational Statistics.

3. Gandara, P., Maxwell-Jolly, J., \& Driscoll, A. (2005). A survey of California teachers' challenges, experiences, and professional development needs. Santa Cruz, CA: The Center for the Future of Teaching and Learning.

4. Stigler, J. \& Heibert, J. (1999). The teaching gap: Best ideas from the world's teachers for improving education in the classroom. New York: The Free Press.

5. Wenglinsky, H. (2000). How teaching matters: Brining the classroom back into discussions of teacher quality, A Policy Information Center Report. New Jersey: Policy Information Center.

6. Bybee, R.W. (2010). Advancing STEM Education: A 2020 Vision. Technology and Engineering Teacher, 3035.

7. McConnell, T.J., Parker, J.M., \& Eberhardt, J. (2013). Assessing teachers' science content knowledge: A strategy for assessing depth of understanding. Journal of Science Teacher Education, 24(4), 717-743.

8. Tretter. T.R., Brown, S.L., Bush, W.S., Saderholm, J., \& Holmes, V.-L. (2013). Valid and reliable science content assessments for science teachers. Journal of Science Teacher Education, 24(2), 269-295.

9. Parker, J.M, McConnell, T.J., \& Eberhardt, J. (2013). Characterizing teachers' incoming science content knowledge in a professional development program. A paper presented at the 2013 Annual International Conference of the National Association for Research in Science Teaching, Rio Grande, Puerto Rico, April 9, 2013.

10. Pecheone, R. and Chung, R. (2006). Evidence in Teacher Education: The Performance Assessment of California Teachers. Journal of Teacher Education. 57: pp. 22 - 36.

11. Riggs, I. M. and Enochs, I.A. (1990). Toward the Development of Elementary School Teachers' Science Teaching Efficacy Instruments. Science Education 74. 625-637.

12. Ragusa, G. \& Mataric, M. (2011) Teacher Training and STEM Student Outcome: Linking Teacher Intervention to Students' Success in STEM Middle and High School Classes. Conference Proceedings: Annual Meeting American Society of Engineering Educators, Vancouver, Canada.

13. Wilson, M. (2012) Constructing Measures: An Item Response Theory Approach. New Jersey, Lawrence Erlbaum. 29-127. 
14. Baker L. \& Wigfield, A. (1999). Dimensions of children's motivation for reading and their relations to reading activity and reading achievement, Reading Research Quarterly, 34, 452-477.

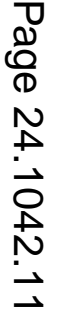

